\title{
Effect of Thickness Reduction on Cold Rolling Process to Microstructure and Brass Hardness
}

\author{
Agung Setyo Darmawan ${ }^{1, *}$, Bambang Waluyo Febriantoko ${ }^{1}$, and Agus Dwi Anggono ${ }^{1}$, Tri \\ Widodo Besar Riyadi ${ }^{1}$, Abdul Hamid ${ }^{2}$ \\ ${ }^{1}$ Department of Mechanical Engineering, Faculty of Engineering, Universitas Muhammadiyah \\ Surakarta, Jl. Ahmad Yani, Tromol Pos 1 Pabelan, Surakarta 57162, Indonesia \\ ${ }^{2}$ Department of Mechanical Engineering, Faculty of Engineering, Universitas Batam, 29464 Batam, \\ Indonesia
}

\begin{abstract}
Brass is an alloy between copper $(\mathrm{Cu})$ and zinc $(\mathrm{Zn})$ where the majority of the elements are copper. Brass that undergoes a cold rolling process will experience changes in microstructure and mechanical properties. This study aims to find out the effect of cold rolling process on changes in microstructure and hardness of brass. The composition of brass is analyzed by using Energy Dispersive Spectroscopy technique, while microscope optic is used to obtain microstructure photograph of brass. The hardness of brass is measured before and after cold rolling process. The test results show that cold rolling process causes the increase of hardness on brass, change of grain shape, and the appearance of deformation bands on brass.
\end{abstract}

\section{Introduction}

Metals have various useful properties such as hard, ductile, and formable. Given these properties, a variety of products are made of metal. The product is produced through a series of process including moulding, forming, machining, welding, heat treatment and surface treatment [1].

One of metal processes is forming. The forming process is classified into a hot forming and cold forming process. The hot forming process is carried out above the recrystallization temperature and the cold forming process is carried out under the recrystallization temperature. The property of that utilized in the forming process is the ductility. Ductility is important for structural materials. Changing the shape is performed by giving plastic deformation [2]. An example of the forming process is rolling.

Large deformations occur in the hot forming process, while small deformations are obtained from cold forming. Metal work is often conducted by heat forming process which is then continued with cold forming. The cold formed metal surface is smoother than the hot formed metal surface.

The cold forming process can make the metal undergo some changes in mechanical properties, namely getting stronger, getting harder, and getting brittle [3,4]. The larger the

\footnotetext{
* Corresponding author: Agung.Darmawan@ums.ac.id
} 
plastic deformation, the greater the strength, hardness and brittleness of the metal. The crack will occur in metal once excessive brittleness is reached. A product has a requirement for mechanical properties, so the process of metal forming must also refer to the requirements of that property [5]. In this case it is necessary to have data on the level of deformation and its relation to the mechanical properties of the material. Therefore it is necessary to test the various levels of deformation and changes in its mechanical properties.

The cold working processes also provide a way to directionally influence the micro structural changes [6-8]. Several researchers have been investigated the effect of plastic deformation to microstructure of material. Li et.al investigated the combination effect of plastic deformation and phase transformation on the evolution of microstructure and property of NiTi alloy [9]. Ren et.al studied grain refinement and mechanical response of U-5.5 wt.\% $\mathrm{Nb}$ alloy produced by cold rolling and heat treatment [10]. Kawalko et.al investigated microstructure evolution of CP titanium during deformation in KoBo process followed by cold rolling [11].

This study aims find out the effect of cold rolling process on changes in microstructure and hardness of brass. Hardness, one of mechanical property that important to consider, is a measure of a material's resistance to localized plastic deformation. Hardness is an indicator of wear resistance [12]. Brass is widely used as an industrial material, clinical and scientific application because of its excellent characteristics such as high corrosion resistance, nonmagnetism, good plasticity deformability, and machinability $[13,14]$.

\section{Materials and Methods}

Several tests are conducted on brass test specimen to reach the objective of this research. The composition of Brass are $62.702 \%$ weight $\mathrm{Cu}$ and $37.298 \%$ weight $\mathrm{Zn}$. The phases of the material are $\alpha$ and $\beta$ '. The tests are as follows:

1. Composition test

2. Cold rolling process

3. Hardness test

4. Metallographic.

The composition of brass is analyzed by using Energy Dispersive Spectroscopy technique. In this way, the element composition can be obtained qualitatively or semiqualitatively on a small area on the surface of the specimen. The cold rolling process is carried out at a temperature below the recrystallization temperature to provide a plastic deformation of the brass specimen in the form of a reduction in the thickness of the brass plate. TBlitz type 2035 roll machine was used in this research. Hardness and metallographic tests are performed at each stage of reduction. Hardness is measured by using Vickers Hardness tester and metallographic test is performed by using microscope optic.

Percent reduction in thickness $(\% R T)$ is defined as

$$
\% R T=\ln \frac{t_{o}}{t_{i}}
$$

where $t_{o}$ is the initial thickness of brass specimen and $t_{i}$ is the instantaneous thickness.

\section{Results and Discussions}

The phases shown in Fig. 1 are $\alpha$ (dark) and $\beta$ ' (light) phases. This corresponds to the $\mathrm{Cu}-\mathrm{Zn}$ phase diagram. There is also a banded structure, a second phase structure that resembles fiber [15]. This structure occurs because alloys have experienced the rolling process and experience segregation of $\mathrm{Zn}$ composition. 
Fig. 1 also shows the colour difference of the $\alpha$ phase (a phase that looks dark and is indicated by B and C). Position B shows a slightly lighter colour than position C. This is due to the $\alpha$ phase at position $\mathrm{B}$ has more $\mathrm{Zn}$ element than that at position $\mathrm{C}$. The atomic number of $\mathrm{Zn}$ is greater than $\mathrm{Cu}$ atomic number. The composition of $\mathrm{Cu}$ and $\mathrm{Zn}$ atoms is shown in the Table 1 .

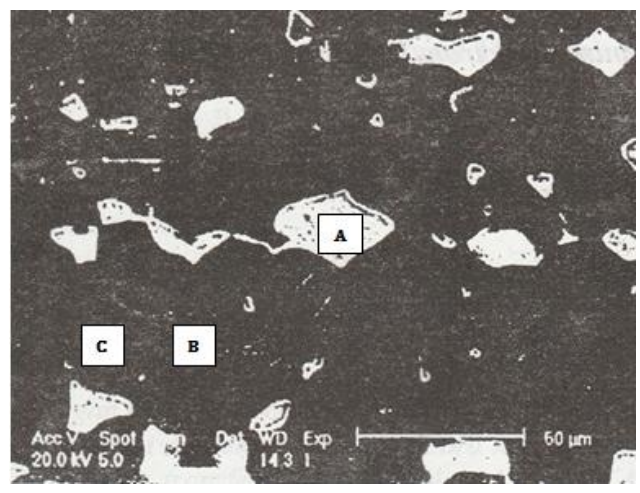

Fig. 1. Scanning Electron Microscopy of Brass

Table 1. The Composition of $\mathrm{Cu}$ and $\mathrm{Zn}$ in brass.

\begin{tabular}{|c|c|c|c|c|}
\hline Position & \% wt Cu & \% wt Zn & \% at Cu & \% at Zn \\
\hline A & 56.565 & 43.435 & 57.261 & 42.739 \\
\hline B & 64.570 & 35.430 & 65.217 & 34.783 \\
\hline C & 65.185 & 34.815 & 65.827 & 34.173 \\
\hline
\end{tabular}

Photographs of metallographic results are shown in Fig. 2 and Fig. 3. Fig. 2 shows microstructure of brass before cold rolling process. The microstructure consists of $\alpha$ phase and $\beta$ ' phase. The annealing twin due to previous hot rolling process appears on the microstructure.

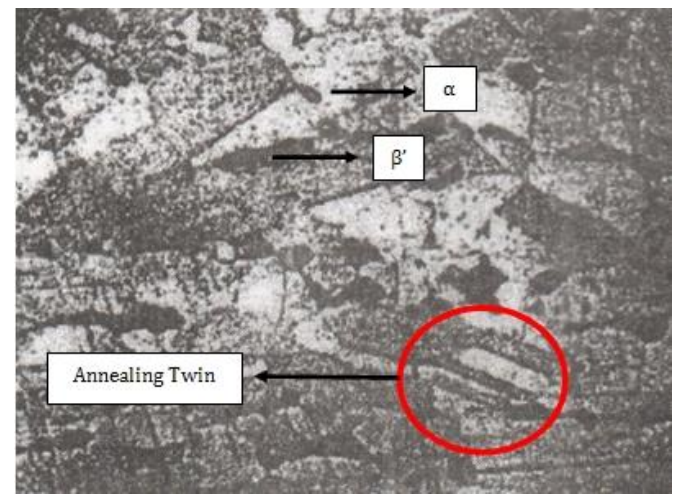

Fig. 2. Initial microstructure photograph of Brass

Fig. 3 shows the microstructure changes because of cold rolling process. It can be seen that the higher the reduction, the grains will be flatter because of deformation. Annealing twin on the reduction in thickness of $10.8 \%$ is deformed so that the shape is slightly curved as can be seen in Fig. 3a. There is no mechanical twinning on the microstructure because the brass has face-centered cubic (FCC) unit cell. 
At a reduction in thickness of $32.9 \%$ to a reduction in thickness of $113.55 \%$ (Fig. $3 \mathrm{~b}$ to Fig. 3f), there is a deformation band in a flat-shaped item. The deformation band is formed because SFE (Stacking Fault Energy) value for brass is low (SFE brass is smaller than $10 \mathrm{~mJ}$ / $\mathrm{m} 2)$.

Fig. 4 shows the effect of reduction in thickness to the hardness. It can be shown that the higher the reduction, the higher the hardness [16]. In this research, hardness increase from 94.3 $\mathrm{HV}$ to $211.7 \mathrm{HV}$. Increasing of hardness is due to the occurrence of strain hardening phenomenon. The strain hardening phenomenon occurs as dislocation dislocations become more difficult to move due to the doubling of dislocations.
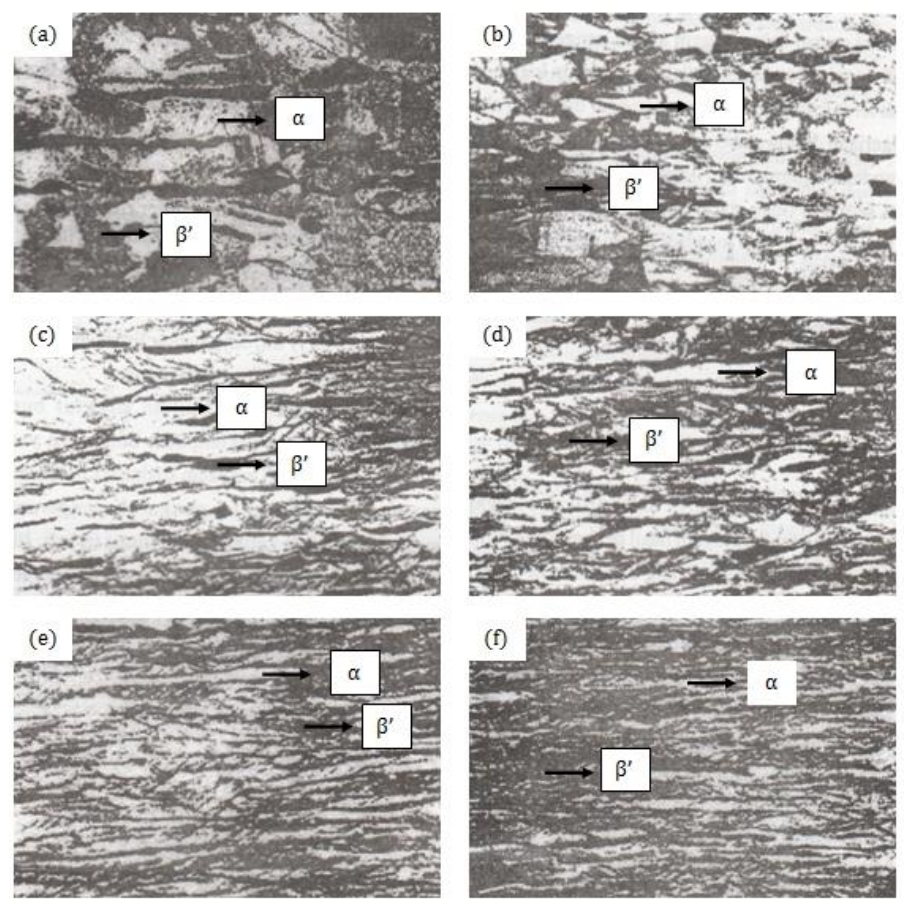

Fig. 3. Microstructure photograph of Brass with reduction in thickness of (a) $10.8 \%$, (b) $32.9 \%$, (c) $57.8 \%$, (d) $78.9 \%$, (e) $94.7 \%$ and (f) $113.5 \%$.

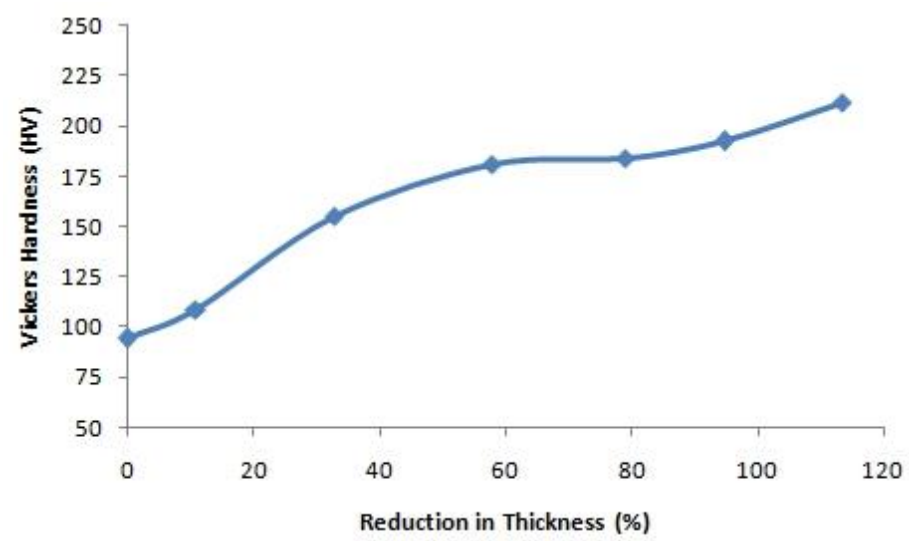

Fig. 4. The effect of reduction in thickness to the hardness. 


\section{Conclusions}

From the result in this research, it is can be concluded as follows:

1. The cold rolling process causes an increase in hardness of brass. In this research, hardness increase from $94.3 \mathrm{HV}$ to $211.7 \mathrm{HV}$.

2. The cold roll process causes the formation of the deformation band on the brass

The authors gratefully acknowledge Mechanical Engineering Laboratory of Universitas Muhammadiyah Surakarta for cold rolling process.

\section{References}

1. A.S. Darmawan, W.A. Siswanto, T. Sujitno, Advanced Materials Research, 789, 347 (2013).

2. Y. Lian, J. Huang, J. Zhang, C. Zhao, W. Gao, Z. Zhang, M. Ma, Materials Science \& Engineering A, 712, 663 (2018).

3. A.S. Darmawan, A.D. Anggono, A. Hamid, MATEC Web of Conferences, 154, 01105 (2018).

4. Y. Bai, T. He, Y. Liu, Materials Characterization, 137, 142 (2018).

5. A. Hamid, I. Baba, W. Sani, International Journal on Advanced Science, Engineering and Information Technology, 7 (2), 446 (2017).

6. C. Lan, Y. Wu, L. Guo, F. Chen, Materials Science and Engineering: A, 690, 170 (2017).

7. S. Wang, L. Niu, C. Chen, Y.L. Jia, M.P. Wang, Z. Li, Z.H. Zhong, P. Lu, P. Li, Y.C. Wu, Fusion Engineering and Design, 125, 510 (2017).

8. M. Eskandari, M.A. Mohtadi-Bonab, J.A. Szpunar, Materials and Design, 90, 618 (2016).

9. Y. Li, J.Y. Li, M. Liu, Y.Y. Ren, F. Chen, G.C. Yao, Q.S. Mei, Journal of Alloys and Compounds, 653, 156 (2015).

10. Z. Ren, R. Ma, G. Hu, J. Wu, Z. Wang, C. Luo, Journal of Nuclear Materials, 494, 72 (2017).

11. J. Kawałko, P. Bobrowski, P. Koprowski, A. Jarze, bska, M. Bieda, M. Łagoda, K. Sztwiertnia, Journal of Alloys and Compounds, 707, 298 (2017).

12. A. S. Darmawan, W. A. Siswanto, T. Sujitno, Applied Mechanics and Materials, 315, 700 (2013).

13. J. Li, Y. Ren, M. Ibrahim, Songbai, K. Yang, Materials Letters, 202, 162 (2017).

14. H. Imai, Y. Kosaka, A. Kojima, S. Li, K. Kondoh, J. Umeda, H. Atsumi, Powder Technology, 198, 417 (2010).

15. J. Ryś, G. Cempura, Materials Science and Engineering: A, 700, 656 (2017).

16. J. Hou, M. Zhang, S. Ma, P.K. Liaw, Y. Zhang, J. Qiao, Materials Science \& Engineering A, 707, 593 (2017). 